\title{
Contribution of medicinal chemistry in Pharm. D curriculum in developing countries
}

\author{
Ramalingam Peraman, ${ }^{1}$ Subish Palaian, ${ }^{2}$ Ansari Mukhtar, ${ }^{3}$ Mohamed Izham Mohamed Ibrahim, ${ }^{4}$ Aljadhey Hisham ${ }^{5}$ \\ 'Department of Medicinal Chemistry, College of Pharmacy, Gulf Medical University, Ajman, UAE. \\ 2Department of Pharmacy Practice, College of Pharmacy, Gulf Medical University, Ajman, UAE. \\ ${ }^{3}$ Department of Clinical Pharmacy, College of Pharmacy, University of Hail, SAUDI ARABIA. \\ ${ }^{4}$ Department of Clinical Pharmacy and Practice, College of Pharmacy, Qatar University, Doha, QATAR. \\ ${ }^{5}$ Department of Clinical Pharmacy, College of Pharmacy, King Saud University, Riyadh, SAUDI ARABIA. \\ Correspondence: \\ Dr. Ramalingam Peraman, M.Pharm, PhD, Assistant Professor of Medicinal Chemistry, College of Pharmacy, Gulf Medical University, Ajman, UAE. \\ Email: drramalingamp@gmail.com \\ DOI: 10.5530/jyp.2016.2.19
}

\section{Dear Editor,}

Doctor of Pharmacy (Pharm. D) Program, a patient oriented pharmacy education curriculum that is new in many of the developing countries and in Gulf Cooperation Council (GCC) countries, and is running with varying success. ${ }^{1,2}$ The conventional industry oriented pharmacy education was unable to fulfill the requirements of healthcare system in terms of direct patient oriented approach and hence there was a necessity of introducing this course. The curriculum of these countries emphasizes on clinical pharmacy, pharmacy practice and provides basic subjects as in other undergraduate pharmacy programs. There has been a voice for the need for change in Pharm D curriculum in developing countries. ${ }^{3}$

Medicinal chemistry is an important branch of pharmacy that involves the application of a number of specialized disciplinary approaches with focus on the ultimate goal of drug discovery, drug target identification and validation, rational (target-based) drug design, structural biology, computational-based drug design, and methods development (chemical, biochemical, and computational) in drug discovery. The field of medicinal chemistry is responsible for developing newer agents of existing class of marketed drugs, in the aspects of milder side effect and more therapeutic effect. Medicinal chemistry is a stimulating field as it links many scientific disciplines and allows for collaboration with other scientists in researching and developing new drugs. ${ }^{4}$ The field of medicinal chemistry differs substantially from pharmacology, although, both pharmacology and medicinal chemistry subjects deal with drugs but in a completely different perspective. Medicinal chemistry provides more logistic orientation to drug action and deals with relationship between structures and their biological effects, gives a structure based reason for comparative pharmacokinetics and pharmacodynamics among drugs and provides an idea for structure modification for better drug design and better 'patient' compliance. ${ }^{5}$ In contrast, pharmacology summarizes the relationship between pathophysiology and drug action and its fate, states a observed effect of pharmacokinetics and pharmacodynamics in patient population and gives an idea for evidence based use of drug for clinical use and for better intervention.

In the purview of the existing curriculum in GCC countries and in India, Pakistan and Nepal; medicinal chemistry subjects are incorporated into the curriculum as separate subjects considering pharmaceutical organic chemistry or pharmaceutical analytical chemistry as prerequisite subjects. It has similar structure that of the conventional industry oriented pharmacy curriculum. The structure and contents in syllabi are not so conducive to improve the clinical skills and competency of a Pharm. D graduates in terms of applying the medicinal chemistry principles. Thus, there is a need to realign the medicinal chemistry curriculum in orientation with pharmacology subjects without neglecting its prerequisites, in such a way medicinal chemistry concepts provide a logical reason for drug

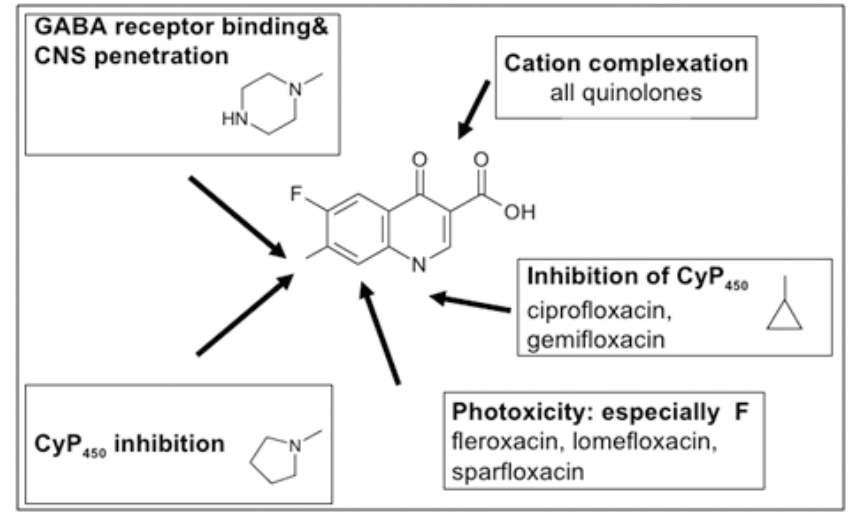

Figure 1: Structure-Pharmacokinetics-toxicity relationship of fluroquinolone

behavior. A sample structure based clinical knowledge required for a clinical pharmacist is shown in Figure 1.

On the other side, there is an existing myth that medicinal chemistry deals only with drug structure, synthesis, and other pharmaceutical chemistry components related to bulk industries which needs a perception change. In reality, it is the subject that can answer and justifies the pharmacological aspects of drugs such as the communication discusses the components including, comparison of medicinal chemistry and pharmacology, significance of medicinal chemistry in clinical practice, and advantages of integration of medicinal chemistry with pharmacology. Table 1 lists some of the examples on significance of relationship between clinical outcomes and medicinal chemistry principles. Moreover, it is one discipline that is not being taught in medical, nursing and other curricula and thus makes pharmacists unique in terms of applying structural correlation with pharmacokinetic and pharmacodynamics properties and thus making them the real expert in drug information and drug therapy monitoring.

In addition to the above factors, another importance of understanding the structure of medicinal products is the explanation of adverse drug reactions (ADRs). Many times, the chemical nature of medicines are responsible for $\mathrm{ADR}$, a simple example being sulphur containing medicines causing allergic reactions in sulphur sensitive individuals. Moreover, at times a particular functional group is implicated for the toxicity of medicines, a common example being nitro group $\left(-\mathrm{NO}_{2}\right)$ being responsible for causing blood toxicity with few drugs including chloramphenicol and metronidazole. Thus, it is evident that causality between the drug and ADR can be established if the observation is supported by biological plausibility. Therefore, understanding the chemical structure of a drug can help identifying ADR and thus a vital role in ensuring patient safety mechanisms. 


\begin{tabular}{|c|c|}
\hline SAR & Clinical correlation (outcome) \\
\hline \multirow{4}{*}{$\begin{array}{l}\text { Catechol is unstable and therefore catechol containing adrenergic } \\
\text { drugs are orally inactive and of shorter duration of action. }\end{array}$} & \\
\hline & - Adrenaline, isoprenaline, dopamine (Catecholamines) etc. are \\
\hline & $\begin{array}{l}\text { - Whereas, salbutamol, terbutaline, salmeterol (non- } \\
\text { catecholamines) are orally active. }\end{array}$ \\
\hline & $\begin{array}{l}\text { - It is only due to oxidizing nature of catechol in the structure of } \\
\text { drug molecule. }\end{array}$ \\
\hline \multirow{2}{*}{$\begin{array}{l}\text { Digoxin and digitoxin, differ structurally with one -OH group at } \\
\text { C-12 position. }\end{array}$} & $\begin{array}{l}\text { This is the reason for more water solubility of digoxin, and there by } \\
\text { renal clearance is more, toxicity is less. }\end{array}$ \\
\hline & $\begin{array}{l}\text { Efficacy is more due to its additional binding of - } \mathrm{OH} \text { group, } \\
\text { responsible for hydrogen bonding with target. }\end{array}$ \\
\hline $\begin{array}{l}\text { Substitution of sulphonamido group in sulphonamide drug, } \\
\text { determine the toxicity (crystalluria). }\end{array}$ & $\begin{array}{l}\text { Nitrogen containing heterocyclics in sulphonamide decreases the } \\
\text { pKa, so that the formed metabolite dissolves in urine. Hence, nature } \\
\text { heterocyclic nucleus determine the degree of renal toxicity. }\end{array}$ \\
\hline $\begin{array}{l}\text { Omeprazole and lansoprazoleare structurally inactive to possess } \\
\text { inhibition of acid in stomach. It has to undergo many structural } \\
\text { changes to be active. This structure activation is possible only in } \\
\text { strong acidic environment. }\end{array}$ & $\begin{array}{l}\text { Thus, it is recommended in the early morning to achieve the } \\
\text { expected efficacy. }\end{array}$ \\
\hline $\begin{array}{l}\text { Among all benzodiazepines; alprazolam, triazolam and oxazepam } \\
\text { are found to be short acting, because of their susceptibility to } \\
\text { metabolism }\left(-\mathrm{CH}_{3} \text { in first two drugs and }-\mathrm{OH} \text { in oxazepam). }\right.\end{array}$ & $\begin{array}{l}\text { Diazepam is long acting, oxazepam is short acting and relatively safe. } \\
\text { Hence, structure residue is determinant of benzodiazepine toxicity. }\end{array}$ \\
\hline $\begin{array}{l}\text { Levo forms (L) of drugs. Levo and Dextro are conventions used to } \\
\text { denote the configuration of 3-D molecule. Example: levocetrizine }\end{array}$ & $\begin{array}{l}\text { The levo forms(a type of stereoisomer) are known to possess lesser } \\
\text { side effects(while preserving efficacy) thanits racemic mixture (Mix } \\
\text { of both isomers). }\end{array}$ \\
\hline
\end{tabular}

Another worrying fact is that the existing knowledge of medicinal chemistry among students and curriculum designers is quite uncertain and narrowed. At times, the curriculum designers are not aware of the extrapolation of medicinal chemistry into clinical practice that might be the reason for considering medicinal chemistry subjects at lesser extent in Pharm. D curriculum. Some even feel that the medicinal chemistry component is not needed in Pharm. D curriculum. This limits the Pharm. D graduates in providing a logistic reason for an action or pharmacokinetics of drug based on their medicinal chemistry knowledge, and often feels burden on chemistry knowledge.

In conclusion, realignment of medicinal chemistry principles in Pharm. D curriculum would be an asset in explaining the pharmacological basis of drug action and its extrapolation to clinical pharmacy practice. This makes Pharm. D graduates more competent member of healthcare team with in depth knowledge on pharmacotherapy and drug selection.

\section{CONFLICT OF INTEREST}

There is no conflict of interest associated with this manuscript.

\section{AUTHOR EXPERTISE AND CONTRIBUTIONS}

Ramalingam $P$ conceptualized the idea and drafted the initial version of the manuscript. He had previous experience in teaching Pharm D students in India.
Subish $P$ added upon the idea and amended the initial version of the manuscript. He also had previous experience of teaching Pharm D students in Nepal.

Ansari $M$ performed the literature review and amended the initial version of the manuscript and is currently teaching Pharm D students in Saudi Arabia.

Izham MIM helped in refining the manuscript and critically commented on the initial version of the manuscript and suggested modifications. Izham MIM, in the immediate past Professorial post at Universiti Sains Malaysia had supervised more than 50 students from GCC countries, Nepal, Pakistan, India and from other developing countries in their MSc and $\mathrm{PhD}$ researches and is actively collaborating with them. Many of his post graduate students were Pharm D holders.

Aljadhey $H$ added few components of the manuscript, especially relating to structural relationships with adverse drug reactions, and suggested modifications in the final version of the manuscript. Aljadhey $\mathrm{H}$ is also the Dean of the College of Pharmacy at King Saud University, Saudi Arabia.

\section{ACKNOWLEDGEMENTS}

Authors would like to acknowledge Dr. Shazia Jamshed, Assistant Professor in the Department of Pharmacy Practice, School of Pharmacy, International Islamic University Malaysia (IIUM) in reviewing the initial version of the manuscript and suggesting modifications.

\section{REFERENCES}

1. Amir M. The after effects of implementing the Pharm D degree in developing countries. Am J Pharm Educ. 2011;75(6):124

2. Jamshed S, Din Babar ZU, Masood I. The Pharm D Degree in Developing Countries. Am J Pharm Educ. 2007;71(6):125

3. Ghayur MN. Pharmacy Education in Developing Countries: Need for a Change. Am J Pharm Educ. 2008;72(4):94.
4. Roche VF, Aitken MJ, Zito SW. Evaluation of computerized medicinal chemistry case study modules as tools to enhance student learning and clinical problemsolving skills. Am J Pharm Educ. 1999;63(3):289-295.

5. Alsharif NZ, Galt KA. Evaluation of an instructional model to teach clinically relevant medicinal chemistry in a campus and a distance pathway. Am J Pharm Educ. 2008;72: Article 31. 